\title{
CARNAVAL NOS ANOS DE 1940 AS MUITAS FANTASIAS DE UM RIO FOLIÃO
}

Helenise Monteiro Guimarães (UFRJ) Raphael David dos Santos Filho (UFRJ)

Este artigo traça breve trajetória das manifestações carnavalescas da cidade do Rio de Janeiro na década de 1940, observando como essas manifestações responderam a eventos históricos como a Segunda Guerra Mundial e o período de governo denominado Estado Novo (19371945). A consolidação do carnaval como festa-símbolo desta cidade é marcada não só pela autoafirmação de sua mais nova e indomável manifestação foliã, o desfile das escolas de samba, mas pela iniciativa do poder público em organizar, de forma sistemática, a ornamentação das principais ruas da cidade. A estratégia seguiria o modelo já consagrado das decorações de bailes, dando à festa nova dimensão, em que a cidade passa por gigantesca metamoforse cenográfica, cuja trajetória muito colaboraria para a espetacularização do carnaval carioca.

FESTAS POPULARES, CARNAVAL, DECORAÇÃO URBANA, ESCOLAS DE SAMBA, RIO DE JANEIRO, BRASIL.

GUIMARÃES, Helenise Monteiro; SANTOS FILHO, Raphael David dos. Carnaval nos anos de 1940: as muitas fantasias de um rio folião. Textos escoIhidos de cultura e arte populares, Rio de Janeiro, v.9, n.1, p. 7-19, mai. 2012. 


\section{CARNAVAL IN THE $1940 \mathrm{~S}$}

THE MANY FANTASIES OF A REVELER RIO DE JANEIRO

Helenise Monteiro Guimarães (UFRJ)

Raphael David dos Santos Filho (UFRJ)

This article traces a brief history of carnaval demonstrations in the city of Rio de Janeiro in the 1940s, observing how these manifestations responded to historical events such as World War II and the period of government called Estado Novo (1937-1945). The consolidation of the carnaval party as a symbol of this city is marked not only by the self-assertion of its newest and indomitable revelers' manifestation - the samba schools parade - but also by the government's initiative to organize, in a systematic way, the ornamentation of the city's main streets. The strategy would follow the already established model of decorations of ball halls, giving the party a new dimension in which the city undergoes a gigantic scenographic metamorphose, whose trajectory collaborates to the very spectacle of Rio's Carnival.

\section{LAR PARTY, CARNAVAL, URBAN DECOR, SAMBA SCHOOLS, RIO DE JANEIRO, BRAZIL.}

GUIMARÃES, Helenise Monteiro; SANTOS FILHO, Raphael David dos. Carnaval nos anos de 1940: as muitas fantasias de um rio folião. Textos escolhidos de cultura e arte populares, Rio de Janeiro, v.9, n.1, p. 7-19, mai. 2012. 


\section{A CONSTRUÇÃO DA MODERNIDADE: A DÉCADA DE 1940 E O CARNAVAL}

No Brasil, a década de 1940 se inicia sob o impacto da Segunda Guerra Mundial e a reordenação da sociedade brasileira. Ortiz (1999, p.38) aponta os anos 40 "como o início de uma 'sociedade de massa', quando se consolida a sociedade urbano-industrial no país, que "se moderniza em diversos setores", devido a fenômenos ${ }^{1}$ que determinaram novos parâmetros culturais (os projetos de construção da nacionalidade e o da integração nacional, entre outros).

O carnaval carioca absorve essas mudanças com a ascensão das escolas de samba e o novo espaço para desfile, a Avenida Presidente Vargas. Oficializado como festa-símbolo da cidade, o carnaval atrai as atenções dos grupos que dividem os espaços centrais da cidade e disputam as subvenções oficiais. As escolas de samba se adequam à nova mentalidade política e fundam a União das Escolas de Samba (1934) com 28 agremiações e estatuto que regulamentava sua finalidade e a apresentação de suas filiadas. ${ }^{2}$

Acompanhando o movimento pela nacionalização, as escolas incluem nesse estatuto a "obrigação de, nos enredos, as escolas de samba apresentarem motivos nacionais" e ainda outros elementos, como a obrigatoriedade da presença das baianas e a proibição dos instrumentos de sopro.

A essas ações soma-se o pedido de oficialização do desfile junto à prefeitura, o que Ihes daria o direito à subvenção, como acontecia com as sociedades, os ranchos e blocos. Em meio a essas competições, houve o desaparecimento da Praça Onze e o surgimento de mais um espaço carnavalesco - a Avenida Presidente Vargas - em função das transformações urbanística na gestão Dodsworth (1937-1945), que "derrubou quarteirões inteiros (...) alterando substancialmente a paisagem do bairro e empurrando seus moradores para outras localidades" (LIMA, 1990, p. 53).

Para marcar a despedida de tão tradicional reduto de foliões, a Praça Onze, a prefeitura encomenda "aos cenógrafos Flavio Leo de Oliveira e Oscar Lopes uma decoração para o espaço ocupado até então pela praça, aludindo ao seu desaparecimento" (CABRAL, 1996, p. 135):

Os cenógrafos montaram dois painéis. Um deles ganhou o título de "A última audiência da baiana" e mostrava uma baiana sentada num trono colocado dentro de um pandeiro. O segundo, chamado "O samba vai mudar-se", exibia um grande pandeiro e, dentro dele, casebres de morro, violões, cuícas, chapéus de palha, etc. 
O primeiro trecho da Avenida Presidente Vargas, entre a Praça da República e a Rua Uruguaiana, foi inaugurado em 10 de novembro de 1942, e o prefeito Dodsworth acentua em seu discurso referindo-se à obra "Não se trata de um espetáculo de aformoseamento da cidade, mas da realização de um programa que procurava resolver problemas econômicos e de saneamento [e] transformar a Cidade Maravilhosa na Cidade das Maravilhas" (LIMA, 1990, p.34).

De fato, ao contrário dos objetivos da denominada Reforma Pereira Passos, que trouxe para a Avenida Central a transposição da cultura europeia e de um novo modo de ser cosmopolita e elegante, a Avenida Presidente Vargas representava uma alternativa na aplicação de recursos, investindo-se no solo urbano, em período de crise, à beira de uma guerra mundial (p. 29).

Coerente com a ditadura civil (1937-1945), o caráter autoritário do Estado Novo é visível nas obras arquitetônicas e urbanísticas e em várias transformações culturais e sociais por que passou a sociedade brasileira naquele período, sobretudo quanto à forma com que eram encaradas suas heranças europeias.

Os anos 40 deixam no Rio de Janeiro as marcas do autoritarismo, que ao mesmo tempo ergue o Palácio Capanema, prédio do Ministério da Educação e Cultura, símbolo da modernidade artística no Brasil e produz uma reforma urbanística que vitima o patrimônio colonial, pela devastação que a Avenida Presidente Vargas provocou, com espaços projetados que "não foram elaborados para serem vividos pelo transeunte, mas para servirem como espaços cênicos, teatrais" (p. 102). E, se a destruição do tecido urbano concorreu para extinguir o lócus fervilhante representado pela Praça Onze, o novo espaço, monumental e distante da escala humana, tendia a impor uma disciplina e "oferecer ao público um cenário para os desfiles militares" (p. 112).

\section{A DECORAÇÃO DA CIDADE E SEU DESENVOLVIMENTO ESTÉTICO, TÉCNICO E SIMBÓLICO}

Da oficialização do carnaval em 1932 até o início da década de 1940, há poucas referências às decorações nas ruas do Centro da cidade. Exceto pela frustrada tentativa de $1928^{3}$ e outras realizadas apenas com o uso de iluminação nos anos 30, a imprensa concedia mais atenção às ornamentações do Baile de Gala do Theatro Municipal e aos coretos dos subúrbios.

Mesmo com as decorações de Gilberto Trompowsky e outros artistas para o Baile de Gala da Cidade, a ornamentação da Avenida Rio Branco até o final da década teria caráter acessório, sobretudo porque ao carnaval 
consagrado como festa popular bastava que a municipalidade fizesse contornar "os troncos e galhos das árvores de fios e lâmpadas elétricas à guisa de lagartas luminosas, de aspecto agradável à vista, contribuindo para o ambiente de festa desejado"(CORREIO DA MANHÃ, 27 de fevereiro de 1936).

No entanto, em 1940 o "carnaval externo", como era chamado o carnaval de rua, é cortejado, e com ele a cidade apresenta ambientação de generosas cores, imagens e formas que não se limitavam às ruas centrais (CORREIO DA MANHÃ, 3 de fevereiro de 1940). ${ }^{4}$ Ainda, coube à prefeitura transformar a Praça Paris em "verdadeiro estádio de luzes e cores", e, estendendo-se até a Praça Mauá, "as árvores se engalanavam de uma espécie de lírios luminosos". Para destacar as ornamentações aplicadas aos postes de iluminação, o Departamento de Propaganda havia mandado colocar refletores, acrescentando também uma novidade: "alto-falantes para distribuir os ritmos sonoros das músicas e aumentar o diapasão das vozes" (CORREIO DA MANHÃ, 3 de fevereiro de 1940).

Roberto DaMatta (1983, p. 87) aponta para a demarcação que o carnaval impõe ao mundo urbano, determinante de muitos espaços, quando podemos observar "ruas inteiras que assumem um aspecto quase privado, relacionandose com suas residências e se abrindo para elas com iluminação e decoração próprias", imagem que se aplica às batalhas de confete da Rua Dona Zulmira, no bairro do Maracanã, com seus desfiles e concursos de fantasias. Afirma ainda que zonas inteiras da cidade podem ser recortadas "de modo que o 'centro' urbano fica partido em muitos nichos - de fato, pequenas praças - onde as pessoas podem encontrar-se e realizar seus carnavais".

Em 1941, a prefeitura multiplica seu empenho para realizar "vistosas ornamentações das praças públicas, quer do centro quer dos arrabaldes", que deveriam apresentar novos motivos, "quebrando aquele ritmo monótono das anteriores", e para tanto foram escolhidos os "motivos infantis tirados da literatura e da cinematografia" (JORNAL DO BRASIL, 1ํ de fevereiro de 1941).

Pela primeira vez o secretário-geral da Administração municipal, Jorge Dodsworth, disponibiliza à imprensa um anteprojeto da ornamentação destinada à Avenida Rio Branco e à Praça Paris. A temática sinaliza o momento cultural que o país vivenciava, com a hibridação da temática infantil nacional e americana e também sinaliza um novo direcionamento técnico na execução dos elementos decorativos, abolindo-se as "caretas" e aumentando-se a iluminação (JORNAL DO BRASIL, 6 de fevereiro de 1941).

Dois elementos aparecem pela primeira vez nas decorações de rua: a unidade temática, que dotou tanto o Centro da cidade como as estações de trens urbanos do Méier, Madureira, Penha, Bonsucesso e Leopoldina dos 
mesmos motivos alegóricos, e um elemento que já existia nos carros alegóricos e mesmos nos coretos suburbanos: o movimento. Dessa forma, o "carnaval externo", o carnaval de rua executado "pelo arquiteto-decorador Flavio Leo da Silva e pelo cenógrafo Oscar Lopes, encarregados de todos os serviços de iluminação e decoração daquele ano, não teria a monotonia visual dos anos anteriores"( JORNAL DO BRASIL, 1ำ de fevereiro de 1941)

A Praça Paris confirma não só essas inovações, mas o fenômeno que Burke (1989, p. 26-27) classifica como “'afinidade' ou 'convergência' entre imagens oriundas de diferentes tradições": "Será erguido nesse local um grupo movimentado, mecanizado, apresentando Rei Momo dando audiência aos astros do cinema infantil. A originalidade do grupo está em Olívia Palito, a noiva do marinheiro Popeye, fantasiada de baiana com balangandãs e figas" (JORNAL DO BRASIL, 1ㅇ de fevereiro de 1941).

No Carnaval de 1942 a decoração chega à recém-inaugurada Avenida Presidente Vargas, e, por determinação da prefeitura, o tema da nova avenida se constituiu de "motivos do carnaval nos morros cariocas", enquanto a Avenida Rio Branco apresentou "baianas, malandros, pandeiros, serpentinas" (JORNAL DO BRASIL, 12 de fevereiro de 1942) e outros elementos característicos da festa e que se tornam definitivamente os símbolos do espaço urbano.

O período da guerra, entre 1943 e 1945, suspendeu a realização do Baile de Gala do Theatro Municipal, mas não impediu que outros espaços fossem tomados pela folia e pela imaginação de cenógrafos como Luiz Peixoto e outros.

Em 1944, o Jornal do Brasil refere-se às restrições impostas pela guerra, que impediam o brilho dos anos anteriores.

O desfile das escolas de samba da União Geral das Escolas de Samba Uges em 1946 foi denominado Carnaval da Vitória, e nele as agremiações já se apresentaram com o modelo de organização que se padronizaria, sempre sofrendo alterações, pelas décadas seguintes ate os dias de hoje. ${ }^{5}$

A decoração da cidade em 1946 foi considerada "paupérrima" e no ano seguinte, foi criada, por Hildebrando de Góes, prefeito do Distrito Federal, a Comissão de Festejos Carnavalescos da Prefeitura que se reúne em 30 de janeiro de 1947 a fim de julgar as propostas para a ornamentação e iluminação da Avenida Rio Branco e da Praça Onze. Essa Comissão, inicialmente, órgão "composto por representantes da Municipalidade, da Polícia e dos Cronistas Carnavalescos",, devido ao sucesso de seus projetos, assumiria caráter permanente, para habilitar a municipalidade "em qualquer época, a promover ou auxiliar nas festas de caráter regional, sem atropelos ou dificuldades"7 (JORNAL DO BRASIL, 4 de fevereiro de 1947). A retomada da ornamentação 
trouxe novidades, como o uso de grandes painéis em madeira compensada, em que foram pintados, entre outros motivos, baianas e piratas, que a imprensa denominou "motivos modernos" e que abordavam as últimas novidades da música.

Com o fim do Estado Novo evoca-se para o carnaval mais liberdade nas brincadeiras do povo. O que se evidencia no discurso dos críticos da época é a grande distância entre o carnaval de rua "horroroso, indigno de uma cidade como o Rio" (JORNAL DO BRASIL, 9 de fevereiro de 1947) e aquele que se realizava nos bailes de classe, muito embora o Baile de Gala fosse um incontestável sucesso. O clamor pelo carnaval de rua à altura da cidade explicitava que a festa deveria estar intrinsecamente ligada à transfiguração da imagem da cidade e deveria apresentar tratamento "artístico" que a tornasse incontestavelmente o maior carnaval do mundo.

O carnaval ao final dessa década já se tornara símbolo do Rio de Janeiro e ditava modelos para o resto do país. Faltava, no entanto que a festa se corporificasse, antes mesmo de seu período oficial, como algo presente na história cultural da cidade. É nesse sentido que o projeto e execução das decorações toma a função metonímica que o caracterizará nas décadas seguintes: escolher, planejar e executar uma ornamentação é assinalar um carnaval vitorioso, capaz de superar os anteriores. A ornamentação passa a ser instrumento de surpresa que a cidade aos poucos revela e expõe à crítica, rejeição ou aceitação dos cidadãos.

Kevin Lynch (1997, p. 140), ao analisar a identificação do homem com a cidade em que vive e com sua paisagem, afirma que certos lugares podem tornar-se tão carregados de significado, que constituem poderoso foco de atenção justamente por estar saturados de "uma longa história cultural e religiosa". E, quanto ao papel ambiental da paisagem, afirma que "o ambiente conhecido por seus nomes e familiar a todos oferece o material para lembranças e símbolos comuns que unem o grupo e permitem que os membros se comuniquem entre si" (p. 143).

Essa relação entre paisagem e ambiente se aproxima muito de uma ideia de decoração urbana carnavalesca capaz de criar a "cidade metafórica" a que se refere Michel de Certeau (apud LYNCH, 1997, p. 143). A cidade engalanada, ordenada em projetos, seria a forma de fixar na memória a imagem de uma festa urbana que constituía seu símbolo maior.

Nesse sentido, a decoração deveria ganhar duplo status, exercer papel metonímico da festa, anunciando-a, e ao mesmo tempo ser metáfora para um mundo carnavalizado sobreposto à paisagem urbana do cotidiano. 
O carnaval carioca já apresentava um passado para o qual contribuíam as formas artisticamente elaboradas das decorações de seus bailes carnavalescos aliadas ao colorido das fantasias dos foliões. No sentido de tornar o carnaval de rua tão "civilizado" quanto aquele dos salões, a decoração começará a conquistar papel fundamental na identidade carnavalesca do Rio de Janeiro. Esse artifício não é inédito, como demonstra Ferreira (2004, p. 181) ao descrever a decoração das ruas centrais da cidade pelas quais, em 1859, passavam os alegres cortejos carnavalescos:

Os enfeites são cada vez mais variados e elaborados e incluem arcos triunfais, bandeiras, festões de flores, estandartes com dísticos, coretos (algumas vezes suspensos sobre as ruas) palmeiras, desenhos de figuras grotescas, galhardetes, queimas de fogos de bengalas, colunas enfeitadas, pirâmides e iluminações a gás, dentre outras novidades.

A pretensão de valorizar a decoração urbana transparece quando, nos preparativos para o Carnaval de 1948, iniciados ainda em 1947, os problemas financeiros e políticos se somaram aos protestos dos candidatos à concorrência pública para a decoração do Centro da cidade. Diante desses protestos e até mesmo ignorando sua veracidade, o apelo feito aos governantes é bem explícito:

Agora o que nos interessa é a população cujas aspirações procuramos interpretar, e que a nossa bela, majestosa e imponente artéria, a Rainha das Avenidas da metrópole, queiram ou não os modernistas e os reformadores de tudo, não apresente ao inteligente, culto e observador povo brasileiro, no grande dia dos folguedos de Momo, ornamentação e iluminação exóticas e ridículas, comprometendo o brilho das comemorações, como já aconteceu várias vezes. A cidade tem todo o direito de exigir que a Avenida Rio Branco ostente, nos dias de carnaval, uma ornamentação digna da sua imponência e do seu merecido título de principal artéria da capital da República, acabando-se de vez com os abusos verificados por todos e que tanto depõem contra os responsáveis pela organização oficial dos festejos carnavalescos. (JORNAL DO BRASIL, 8 de janeiro de 1947)

Porém, os "coretos de roça", como chamou o cronista A.Zul as estruturas montadas na Avenida Rio Branco compartilharam o espaço com a ornamentação planejada, que por sua vez não atendeu às expectativas por falhas técnicas em sua montagem. Essa frustrante tentativa logo seria compensada no ano seguinte, quando a Praça Floriano recebe uma rica "baiana 
existencialista"8 e, na Avenida Rio Branco, "os arcos ficaram de pé, o que como todos sabem, não ocorreu ano passado" (CORREIO DA MANHÃ, 27 de fevereiro de 1947).

Para o carnaval do Centro da cidade foi importante o estabelecimento dos pontos de concentração nas áreas em se apresentavam os grupos carnavalescos. Se o trajeto por eles percorrido ou ocupado já há algumas décadas fixava alguns locais como espaços carnavalescos, a decoração os demarcaria diferenciando-os do espaço comum da cidade.

O que o estabelecimento das decorações urbanas coloca como solução para um carnaval que aparentemente estava enfraquecido em sua imagem urbana é justamente a afirmação do caráter de uma cidade "carnavalesca" e, em última instância, a afirmação da Cidade Maravilhosa como a cidade do "verdadeiro carnaval". É assim que na malha urbana vemos consolidados a Praça Onze, a Praça Paris, a Praça Marechal Floriano, o Obelisco, a Avenida Rio Branco, a Avenida Presidente Vargas, a região da Candelária como espaços carnavalescos demarcados pelas ornamentações. Para o desenho da "cidade do carnaval" eles configuram locais fundamentais de reconhecimento do cidadão da proximidade e instalação da festa. O estabelecimento de uma unidade temática e o reforço de determinados pontos como "marcos" serão fundamentais, como veremos no transcorrer das décadas, para a fixação, na memória da cidade, de uma tradição ornamental para o carnaval.

Se havia união de todas as expressões com o poder público para reafirmar o padrão internacional da festa, ${ }^{9}$ esse mesmo poder público estimulava a competição a cada desfile (CORREIO DA MANHÃ, 27 de fevereiro de 1949).

O Carnaval de 1949 apresenta o Rio de Janeiro imerso na preocupação de sua reabilitação como grande festa internacional, para o que não se mediriam esforços na produção de um carnaval à altura da tradição carioca.

O caráter espontâneo largamente difundido como paradigma da festa carnavalesca era reforçado por uma ideia de libertação e loucura, sendo a própria cidade seu maior agente produtor (CORREIO DA MANHÃ, 3 de março de 1949, p. 21).

\section{O CARNAVAL INSPIRANDO A ARTE CENOGRÁFICA}

No final dos anos 40 o carnaval começa a representar também para o artista um modo de popularizar seu trabalho. Outro dado importante é a visão do carnaval como elemento de hibridação de várias técnicas artísticas, conjugadas pela "arte cenográfica de carnaval". ${ }^{10}$ Se antes esse artista erudito 
pouco valor dava a essa atividade, ele passa a aproveitar a oportunidade que é oferecida para a "expansão de sua arte criadora". ${ }^{11} \mathrm{O}$ fato de estar realizando "notável obra de educação artística"12 reflete bem a determinação das elites de fazer do carnaval veículo de mensagens pedagógicas, destacando-se a imagem de nação, que se faz onipresente na cultura.

É possível detectar nesses movimentos as diferentes correntes culturais já atuantes na sociedade como fonte de padrões que coexistiam sob determinado contexto - o carnaval. Nesse caso, os participantes dessa cultura carnavalesca, populares e eruditos, interagem e remodelam seus projetos, acompanhando as transformações implantadas pelas políticas culturais estabelecidas para organização do carnaval carioca.

As já desgastadas estratégias de repressão policial às manifestações consideradas inadequadas vinham sendo aos poucos substituídas por um projeto cultural que envolvia intelectuais, poder público e também as elites, pretendendo integrar essas manifestações ao padrão civilizado da festa. A tarefa constante de domesticar uma "selvageria" latente de alguns segmentos da sociedade, que no carnaval encontravam sua forma de vir à tona imbricadas nos ritmos, danças e combates, buscava através de uma reeducação reinterpretar "adequadamente" e descartar "toda a tendência rebelde, explosiva e incontrolável destes segmentos" (couTINHO, 2006, p.25).

Essa definição de um carnaval cada vez mais civilizado não quer dizer que ele passe a ser uma festa mais igualitária, tendo em vista que as diferenças estão constantemente sendo demarcadas e redefinidas. Não se pode esquecer que o poder público praticamente é obrigado a incluir o povo e suas manifestações em seu programa oficial de carnaval, embora esses segmentos devam fazer concessões para participar da festa. E uma das formas que determinam ser essa festa única, diferente e elegante para todos, é fornecer à cidade uma nova imagem do cotidiano carnavalesco. É por esse motivo que as ornamentações urbanas não poderiam se ater ao âmbito da cultura popular ou da cultura erudita, antes retirando de ambas subsídios para suas narrativas e técnicas. Ela se constitui então estratégia originária do processo que incluiu o carnaval na indústria cultural porque a natureza de seu público muda. 0 carnaval tem seu público alterado e será realizado cada vez mais para as massas, ${ }^{13}$ aí incluídos todos os segmentos que dele participam.

\section{CONSIDERAÇÕES FINAIS}

O carnaval e os agentes que produzem suas artes visuais, se aplicarmos o pensamento de Fredrik Barth (2000, p. 123), "participam de universos de 
discursos múltiplos, mais ou menos discrepantes, constroem mundos diferentes, parciais e simultâneos, nos quais se movimentam. A construção cultural que fazem da realidade não surge de uma única fonte e não é monolítica".

Trata-se de construção cultural que é resultado da soma de todas as expressões carnavalescas até os anos 50 . 0 que a diferencia na década seguinte é o estabelecimento de novas estratégias de produção, ditadas pelo posicionamento dos agentes e as trocas culturais cada vez mais velozes e intensas que atingiriam o carnaval carioca.

\section{REFERÊNCIAS BIBLIOGRÁFICAS}

ARAUJO, H. Carnaval, seis milênios de história. Rio de Janeiro: Gryphus, 2003.

BARTH, Fredrik. O Guru, o iniciador e outras variações antropológicas. Rio de Janeiro: Contracapa, 2000.

BURKE, Peter. A cultura popular na idade moderna. São Paulo: Companhia das Letras, 1989.

CABRAL, Sergio. As escolas de samba do Rio de Janeiro. Rio de Janeiro: Lumiar Editora, 1996.

COUTINHO, Eduardo Granja. Os cronistas de Momo. Imprensa e carnaval na Primeira República. Rio de Janeiro: Editora UFRJ, 2006.

DAMATTA, Roberto. Carnavais, malandros e heróis: para uma sociologia do dilema brasileiro. Rio de Janeiro: Zahar, 1983.

FERREIRA, Felipe. O livro de ouro do carnaval brasileiro. Rio de Janeiro: Ediouro, 2004.

. Inventando carnavais: o surgimento do carnaval carioca no século XIX e outras questões carnavalescas. Rio de Janeiro: Editora UFRJ, 2005. (Col. História Cultura e Ideias, v.3)

GUIMARÃES, Helenise Monteiro. A batalha das decorações: a Escola de Belas Artes e o carnaval carioca. Tese (doutorado) - Escola de Belas Artes, Universidade Federal do Rio de Janeiro, Rio de Janeiro, 2006.

LIMA, Evelyn Furquim Werneck. Avenida Presidente Vargas: uma drástica cirurgia. Rio de Janeiro: Secretaria Municipal de Cultura, 1990. (Coleção Biblioteca Carioca, v. 12)

LYNCH, Kevin. A imagem da cidade. São Paulo: Martins Fontes, 1997.

MARTIN-BARBERO, Jesus. Dos meios às mediações: comunicação, cultura e hegemonia. Rio de Janeiro: Editora UFRJ, 2003.

ORTIZ, Renato, A moderna tradição brasileira, São Paulo: Brasiliense, 1999.

RIBEIRO, Ana Paula Goulart. Jornalismo, literatura e política: a modernização da imprensa carioca nos anos 1950. Estudos Históricos, Rio de Janeiro, v. 1, n. 31 (Mídia), 2003. 


\section{NOTAS}

10 autor refere o "crescimento da industrialização e urbanização, a transformação do sistema de estratificação social, com a expansão da classe operária e das camadas médias, o advento da burocracia e das novas formas de controle gerencial, o aumento populacional e o desenvolvimento terciário em detrimento do setor agrário" (ORTIZ, 1999, p. 38-39).

2 A finalidade maior da União das Escolas de Samba era "organizar programas de festejos carnavalescos e exibições públicas, entender-se diretamente com as autoridades federais e municipais para obtenção de favores e outros interesses que revertam em benefício de suas filiadas" (CABRAL, 1996, p. 97).

3 A prefeitura da cidade nesse ano pela primeira vez ornamentou a Avenida Central com elementos do universo carnavalesco, de autoria do cenógrafo Luiz Peixoto, porém a iniciativa não teve repercussão junto ao público.

4 Nos bairros, os coretos e as ruas decoradas atraíam o público, o que também acontecia nos logradouros centrais da cidade, sendo a Avenida Rio Branco a "figura central de um imenso caleidoscópio" (CORREIO DA MANHÃ, 3 de fevereiro de 1940).

5 "Nas décadas de 40-50, as escolas de samba completam o ciclo de formação e constituem "espinhas vertebrais" básicas compostas pelo enredo, sambade-enredo, alegorias e fantasias. Esses arcabouços dão identidades próprias às escolas de samba. Já é possível diferenciá-las dos blocos carnavalescos, ranchos carnavalescos e grandes sociedades" (ARAUJO, 2003, p.186).

6 Com a firme intenção de "orientar e incentivar a grande festa popular do Brasil que (...) estava em plena decadência" a Comissão foi presidida "pelo Dr. João Pequeno de Azevedo, diretor do Departamento de Turismo, e formada pelos Srs. Vieira de Melo, diretor do Departamento de Difusão Cultural; Álvaro Pinto da Silva, jornalista e representante da Sala de Imprensa da Prefeitura; Rubens de Rezende, representante da Sala de Imprensa da Polícia, Armando dos Santos, presidente da Associação de Cronistas Carnavalescos, e Lourival Dalier Pereira, Antonio Veloso e o redator desta seção, jornalistas especializados, que, como é fácil constatar, já asseguram o início do ressurgimento da maior festa do povo brasileiro" (JORNAL DO BRASIL, 4 de fevereiro de 1947).

7 Os comentários são do cronista A.Zul, um dos mais ativos defensores da ornamentação da cidade, que nesse ano havia sido vencida através de concorrência pública pelo Estúdio Eurico. É a partir do final dos anos 40 que tanto artistas autônomos quanto firmas começam a se candidatar para as eventuais licitações lançadas pela municipalidade. É nesse ano também que essa Comissão delibera pela obrigatoriedade dos motivos nacionais, tanto para as ornamentações da cidade quanto para os enredos dos ranchos.

8 Infelizmente as descrições desse elemento decorativo não fazem referências quanto ao que o articulista denominou "baiana existencialista"; também não foram encontradas foto nos arquivos pesquisados.

9 Segundo Ferreira (2005, p. 213), já nas primeiras décadas do século XX o carnaval carioca disputava a primazia mundial como maior festa popular do 
mundo. "O carnaval carioca, definindo-se como festa que abrange toda a cidade e que expressa a cultura do país, torna-se, não só uma manifestação grandiosa mas também - e isso é o mais importante - uma manifestação própria da cidade, um produto específico do espaço urbano carioca e uma festa inigualável. Festa capaz de atrair a atenção do mundo e de servir como um polo de atração turística e de geração de divisas, marcando uma imagem individualizada para a cidade e o país."

10 Em 12 de fevereiro de 1949 Daniel Fonseca, articulista do Correio da Manhã, publica longo artigo apresentando a festa carnavalesca como campo de trabalho para criações artísticas: "O carnaval carioca tem contribuído bastante para o desenvolvimento da arte brasileira oferecendo ao observador aspectos curiosos e dignos de reparo. Os artistas plásticos nacionais recebem com prazer a oportunidade que os festejos de Momo oferecem à expansão de sua arte criadora. Neles realiza o cenógrafo patrício, em três dimensões, notável obra de educação artística popular. Decorando salões de baile, ornamentando as principais avenidas e praças da metrópole, ou confeccionando os tradicionais préstitos alegóricos, a família artística se reúne em grupos e, em competições memoráveis, disputa os lauréis da vitória (...) As principais obras literárias e artísticas têm sido realizadas nas alegorias de carnaval, pela pintura e pela escultura, conjugadas na cenografia. Também os costumes típicos, a flora e a fauna, nas concepções decorativas, têm motivado imponentes préstitos, elevando a fama de muitos artistas, popularizando-lhes o nome. A preocupação em apresentar temas originais da singular fisionomia da nossa arte cenográfica de carnaval, tornando-a, segundo testemunhas (...) única no mundo, situada muito acima das que realizam em Nice e Veneza: verdadeiros manipansos em desfile" (FONSECA, Daniel Jornal do Commercio, 13 de março de 1949 apud GUIMARÃES, 2006, p. 160-161).

11 Guimarães, Helenise Monteiro, op. cit., p. 160.

12 Id.ibid., p.160.

13 Segundo Martín-Barbero (2003, p.179), massa designa, no movimento de mudança, o modo como as classes populares vivem as novas condições de existência, tanto no que elas têm de opressão quanto no que as novas relações contêm de demanda e aspirações de democratização social. E de massa será a chamada cultura popular.

Helenise Monteiro Guimarães é professora e vice-diretora da Escola de Belas Artes, Universidade Federal do Rio de Janeiro.

Raphael David dos Santos Filho é professor-associado da Faculdade de Arquitetura e Urbanismo, Universidade Federal do Rio de Janeiro. 
